Vol 11, Issue 8, 2018

\title{
COMPARING THE EFFECT OF TWO METHODS OF ANESTHESIA INDUCTION ON CONSCIOUSNESS DURING ORTHOPEDIC SURGERY
}

\author{
FARHAD NANAEI ${ }^{1}$, SARA ADARVISHI ${ }^{2}$, MARYAM DASTOORPOOR ${ }^{3}$, ZOHRE SEKHAVATPOUR ${ }^{4 *}$ \\ ${ }^{1}$ Department of Anesthesiology, School of Medicine, Dezful University of Medical Sciences, Dezful, Iran. ${ }^{2}$ Department of Anesthesiology, \\ School of Paramedicine, Student Research Committee, Ahvaz Jundishapur University of Medical Sciences, Ahvaz. ${ }^{3}$ Department of \\ Epidemiology, Air Pollution and Respiratory Diseases Research Center, Ahvaz Jundishapur University of Medical Sciences, Ahvaz, Iran. \\ ${ }^{4}$ Department of Anesthesiology, School of Paramedicine, Dezful University of Medical Sciences, Dezful, Iran.
} Email: sekhavat.z@dums.ac.ir

Received: 19 February 2018, Revised and Accepted: 21 April 2018

ABSTRACT

Objectives: Consciousness during anesthesia is a non-reversible complication that may expose the patient to severe, long-term, emotional injuries and post-traumatic stress. Therefore, this study aimed to compare the effect of two methods of induction maintenance of anesthesia with thiopental sodium-remifentanil and propofol-alfentanil on consciousness during orthopedic surgery using a bispectral index (BIS) device.

Methods: In this triple-blind clinical trial, 111 patients who underwent orthopedic surgery in Dezful Hospital (southwestern Iran) were investigated. Patients were randomly assigned into two groups: The intervention Group " $\mathrm{A}$ " received thiopental for the induction of and fentanyl for maintenance and intervention Group "B" received propofol and alfentanil. The patients underwent BIS monitoring before the end of surgery, and the BIS value was recorded. The Brice questionnaire was used to measure the consciousness. The data were analyzed using repeated Measure ANOVA test.

Results: In the intervention Groups A and B, the mean BIS score was 63.71 and 60.62 in the first 5 min after surgery, reaching 65.25 and 67.7360 min after surgery, respectively. The results of repeated measures ANOVA test showed that the mean BIS score was significantly different from the preoperative value (baseline) group during repeated measurements after surgery $(5,10,15,30,40$, and $60 \mathrm{~min})(\mathrm{p}<0.001)$. According to the Brice questionnaire, the prevalence of hearing loss during surgery showed a statistically significant difference between the two intervention Groups (A and B), and the incidence of hearing during surgery in intervention Group "B" was approximately 3 times higher than intervention Group " $\mathrm{A}$ " (odds ratio $=3.22,95 \%$ confidence interval: $1.32-7.79$ ).

Conclusion: The results indicate that none of the induction and maintenance pharmacologic methods have any superiority in terms of optimal depth of anesthesia in patients undergoing orthopedic surgery.

Keywords: Recall, Surgery, Anesthesia awareness, Bispectral index monitoring, Consciousness during anesthesia.

(c) 2018 The Authors. Published by Innovare Academic Sciences Pvt Ltd. This is an open access article under the CC BY license (http://creativecommons. org/licenses/by/4. 0/) DOI: http://dx.doi.org/10.22159/ajpcr.2018.v11i8.25370

\section{INTRODUCTION}

Consciousness and recalling surgical events during general anesthesia have always been important problems for patients and anesthesiologists [1]. If the patient experiences pain, he/she will undergo serious mental and psychological complications, identified as neurosis, and if the person is consciousness during the operation and is able to hear the conversations during the operation, he/she will feel weakness, frustration, helplessness, anxiety, and horror of death. Furthermore, the inadequate concentrations of drugs, malfunction of tubes or drug infusion pumps, and error of anesthesiologist may be involved in its occurrence. Conventionally, hemodynamic parameters were used to assess the depth of anesthesia, such as blood pressure, heart rate, or objective evidence such as patient's movements, tearing, or sweating, but these methods are not accurate and are always subject to errors. For example, using beta-blockers by the patient before surgery prevents hemodynamic changes during anesthesia; therefore, the use of more precise methods is recommended $[2,3]$. In this regard, the evaluation of brain function during anesthesia is considered a screening method, and accordingly, bispectral index (BIS), auditory evoked potential index, and patient state index were evaluated [4]. Certainly, electroencephalogram waves are affected by anesthesia and different wave patterns are observed during stages of anesthesia, which can be used processed or unprocessed/raw. Using the raw form is difficult because it is very complex and is influenced by artifacts, and its interpretation requires an experienced person [5].
This device offers a small computer using these index waves known as BIS monitoring. Previously, this index was used to measure the depth of anesthesia [6]. Furthermore, patient's recovery and extubation time decreased, and undesirable results, such as consciousness, during surgery were prevented [7]. In addition, Kamali et al. conducted a study to measure the effect of BIS monitoring on the level of awareness during anesthesia in women undergoing cesarean section. The results showed that the incidence of consciousness during anesthesia in the group with BIS monitoring significantly decreased compared to the control group [8]. Furthermore, Szostakiewicz et al. studied general anesthesia awareness and the patient responded to 5 questions after recovery from anesthesia. The results showed that the use of adequate concentration of inhaled drugs reduced general anesthesia awareness or consciousness during surgery [9]. The incidence of anesthesia awareness varies by multiple factors affecting it. Little research has addressed the prevalence of anesthesia awareness in different surgical procedures in Iran. According to the statistics obtained in the second half of the year 2014 and the first 3 months 2015, 7,243 surgeries (approximately 700-800 cases/month) were performed in Ganjavian Hospital in Dezful, of which about 3000 were orthopedic surgeries and about $70 \%$ of total anesthesia performed were general. Considering the high use of this type of anesthesia, addressing this issue is one of the most important and significant issues. Since several drug categories are commonly used for the induction and maintenance of anesthesia, and this study aims to compare two protocols of induction with thiopental sodium and maintenance with remifentanil versus induction with 
propofol and maintenance with alfentanil on the depth of anesthesia, evaluated by BIS device in patients undergoing orthopedic surgeries in the operating theater of Dezful Hospital in 2017, to indicate the drug category which is the most effective in preserving and maintaining the depth of anesthesia during surgery.

\section{METHODS}

This randomized, triple-blind, clinical trial study investigated the rate of consciousness during surgery measured by BIS, comparing two anesthetic methods of induction maintenance with thiopentalremifentanil and propofol-alfentanil. This article is the result of a research project with the Ethics code of Ir.dums.rec.1395.8

The sampling method in this study was convenient and available and based on the eligibility of patients to participate in the study. For this purpose, the researcher referred to the research environment in morning, evening, and night shifts from October 2016 to July 2017 and interviewed eligible patients.

Since, in this hospital, patients underwent general surgery in several procedures, including orthognathic, gynecology, orthopedics, urology, neurosurgery, and open heart surgery, samples were selected from orthopedic patients due to the higher burden of these patients in this center than the rest of patients. At the beginning of the sampling, samples were matched based on age, gender, and history of previous anesthesia. Then, each pair was placed in two Groups (A and B) by simple random allocation method.

Samples consisted of 111 patients including men and women surgical ward of Dezful Hospital (Iran), 2017. The inclusion criteria consisted of male and female patients aged 16-45 years with healthy and normal mental and intellectual state, being able to talk and communicate, speaking Farsi, with ASA Class I/II, and with the maximum duration of surgery of 60-90 min. Exclusion criteria: Patients with low survival chance; intubated within $24 \mathrm{~h}$ after anesthesia due to postoperative complications, emergency patient; traumatic patient; and noncooperation to recover from anesthesia were excluded from the study.

\section{Sampling size}

In this study, due to the lack of any similar study, a pilot study was first performed on 20 patients in intervention Group " $\mathrm{A}$ " and 20 patients in intervention Group "B." Given that, mean pre-operational BIS was $98.5 \pm 1.4$ and $97.76 \pm 1.8$ in intervention Groups A and B, respectively, and considering $95 \%$ confidence level, test power $80 \%$, and standard deviation $\left(\mathrm{SD}_{1}\right)=\mathrm{SD}_{2}=1.4$, and using the following formula, the final sample size was estimated at 57 people in each intervention Group "A" and $\mathrm{B}$.

$$
\mathrm{n}=\frac{\left(s_{1}^{2}+s_{2}^{2}\right)^{2}\left(z_{1-\frac{a}{2}}+z_{1-\hat{a}}\right)^{2}}{(\bar{x} 1-\bar{x} 2)^{2}}
$$

There was one dropout in the intervention Group "A" and two in intervention Group "B," in this study. Finally, 56 patients in intervention Group "A" and 55 patients in intervention Group "B" entered the final analysis.

In this study, all subjects under general anesthesia were randomly assigned into one of the two following groups: Intervention Group "A" received $3-5 \mathrm{mg} / \mathrm{kg}$ thiopental sodium, $0.2-0.4 \mathrm{mg} / \mathrm{kg}$ atracurium, $0.1 \mathrm{mg} / \mathrm{kg}$ midazolam, $0.1 \mathrm{mg} / \mathrm{kg}$ morphine, and $1-3 \mu \mathrm{g} / \mathrm{kg}$ fentanyl, and intervention Group "B" received 1-2.5 mg/kg propofol, $0.2-0.4 \mathrm{mg} / \mathrm{kg}$ atracurium, $0.1 \mathrm{mg} / \mathrm{kg}$ midazolam, $1-3 \mu \mathrm{g} / \mathrm{kg}$ fentanyl, and $0.1 \mathrm{mg} / \mathrm{kg}$ morphine. Then, to maintain anesthesia in Group "A," $50 \%$ oxygen gas and 50\% N20 gas, 0.2-0.6 MAC isofluorine, and $0.05-2.5 \mu \mathrm{g} / \mathrm{kg} / \mathrm{min}$ remifentanil were used, and for Group "B," 50\% oxygen and 50\% N2O gas, $0.2-0.6$ isofluorine gas MAC, and 2-10 $\mu \mathrm{g} / \mathrm{kg} / \mathrm{min}$ alfentanil were used. The researcher was present at patients' bedside after the anesthesiologist induced anesthesia and recorded patients' BIS and vital signs at minutes $5,15,30,40$, and 60 . Then, $24 \mathrm{~h}$ after anesthesia, the researcher asked questions about awareness and consciousness from the patient under anesthesia on Brice questionnaire.

The blinding method in this study required that the patients not know the type of assignment to intervention Groups " $\mathrm{A}$ " and " $\mathrm{B}$ " and not know what protocol he/she was to be received. Meanwhile, the anesthesiologist and the main researcher were also unaware of the type of allocation and did not know what kind of anesthetic intervention was injected to the patient for induction and maintenance.

Furthermore, the researcher was instructed to record BIS number and vital signs without being aware of the type of grouping. After the operation, they completed the questionnaire by interviewing the patient without knowing which patient was in which drug group. Finally, the statistician who performed the statistical analysis was unaware of the patient grouping. It should be noted that the only person who was aware of the patient allocation into Groups "A" or "B" and knew the type of drug delivered to the patient received the completed questionnaires from the researcher and placed them in the relevant group folders. Finally, the folders were coded as "A" and "B" and delivered to the statistician.

\section{Data collection tools}

The tools used in this study included the selection of research units (designed based on inclusion and exclusion criteria and completed by interview and reviewing the patient's records), personal characteristics (containing questions about personal characteristics and patient records, completed by interview and reviewing the patient's records), assessment of vital signs (containing the patient's vital signs including human resources, business partner, T, RR, and BIS measured before, during, and after anesthesia).

\section{BIS device (device for measuring the depth of anesthesia)}

This device measured the patient's awareness and consciousness during the operation based on the following categories: 85-100 was equal to consciousness, 065-85 sedation, 40-65 general anesthesia, 30-40 deep hypnosis, and 0-30 burst suppression. The device used for this purpose was BIS VISTA, made by AS PECT MEDICAL, USA.

\section{BRICE awareness and consciousness under anesthesia}

This form, designed by Brice in 1970 and later modified by Liu in 1991, collects the information about consciousness and awareness during surgery using interviews with patients after anesthesia $[10,11]$.

For confirming the validity of the instrument, content validity was used by recording the selection of research units, personal characteristics, vital signs, BIS device (depth of anesthesia measurement), patients' awareness, and consciousness during anesthesia (Brice). For this purpose, the sheets were selected by studying the latest books and articles in the research field and were then evaluated by 10 Faculty Members of Dezful University of Medical Sciences and experts, and after considering their suggestions, the necessary changes were made and the final version was prepared. For the purpose of determining the reliability of the tool, the selection of research units, personal characteristics, vital signs, and the BIS device (depth of anesthesia measurement) were designed by reviewing the references in the research field with a clear and objective questionnaire and device and used frequently in similar studies. Therefore, its reliability was confirmed, and the reliability of BRICE was confirmed during the pilot study by a Cronbach's Alpha of 0.7 .

\section{Statistical analysis}

After the completion of data collection, the forms were coded and entered into the computer, and after ensuring the accuracy of the data entry, the data were analyzed by SPSS version 22 and the following statistical methods were used. First, the normal distribution of the 
quantitative variables was determined by Kolmogorov-Smirnov test. To describe patients' characteristics, descriptive statistics including mean, SD, and frequency were used. To compare the baseline variables and the rate of consciousness during operation between two interventional Groups " $\mathrm{A}$ " and "B," independent t-test and Chi-square test were used.

Furthermore, repeated measures ANOVA (RMA) test was used to evaluate the effect of repeated variables in intervention Groups "A" and "B" at 7 time points: Before intervention, 5, 10, 15, 30, 40, and $60 \mathrm{~min}$ after surgery.

To use RMA test, first, the Mauchly's test of sphericity condition was tested for the dependent variable, and the results indicated that the assumption was not satisfied $(\mathrm{p}<0.05)$. Therefore, to study the net effect of time and the simultaneous effect of time and group, the results of Greenhouse-Geisser test were used. The significance level was considered $<0.05$.

\section{RESULTS}

Of 111 patients, $94(84.7 \%)$ were male and the rest were female. The mean age and weight of patients were $32.57 \pm 12.10$ years and $76.59 \pm 14.45 \mathrm{~kg}$, respectively. In terms of educational level, 22 $(19.8 \%)$ had academic education and the rest were high school graduates or lower. Regarding the number of previous procedures, $104(93.7 \%)$ had 1-2 times surgery, and only 7 (6.3\%) had no history of surgery; $17.1 \%$ (19 people) reported alcohol abuse. The results of bivariate test showed that the two intervention Groups " $\mathrm{A}$ " and
"B" were homogeneous in terms of demographic variables before intervention, and there was no significant difference between them (Table 1).

According to the results of Table 2, the mean and SD of anesthesia depth [BIS] changed before and after $(5,10,15,30,40$ and 60 minutes) surgery in both intervention groups of A and B in Table 2. In intervention Group A, mean BIS score changed from 63.71 in the first $5 \mathrm{~min}$ after surgery to 65.65 at $60 \mathrm{~min}$ postoperatively, and the results of RMA test showed a significant difference in mean BIS score during repeated measurements after surgery $(5,10,15,30,40$, and $60 \mathrm{~min})$, compared to pre-operational values (baseline) $(\mathrm{p}<0.001)$.

In intervention Group "B," mean BIS score was 60.62 in the first 5 min after surgery that reached 67.73 at 60 min after surgery, and the results of RMA test showed a significant difference in mean BIS score during repeated measurements after surgery $(5,10,15,30$, 40 , and $60 \mathrm{~min}$ ), compared to pre-operational values (baseline) $(\mathrm{p}<0.001)$.

The significance of the changes in the two groups was also tested in relation to each other, according to which the mean score of BIS at preoperative time and $5,10,15,30,40$, and 60 min after the surgery was not significantly different $(\mathrm{p}>0.05$ ) (Table 2$)$.

In Table 3, the patients' experience of consciousness during surgery was evaluated in both Groups "A" and "B" using Brice questionnaire. As can be seen in questions 1-5 of Brice questionnaire, the prevalence

Table 1: Distribution of demographic variables among the study groups ${ }^{\circ}$

\begin{tabular}{|c|c|c|c|}
\hline Variables & Intervention Group A n=56 & Intervention Group “B” n=55 & $\mathbf{p}$ \\
\hline Age, year & $33.32(12.1)$ & $31.8(12.2)$ & $0.510^{\mathrm{b}}$ \\
\hline Weight, kg & $77.8(14.9)$ & $75.4(14.1)$ & $0.387^{\mathrm{b}}$ \\
\hline \multicolumn{4}{|l|}{ Sex } \\
\hline Male & $44(78.6)$ & $50(90.9)$ & \multirow[t]{2}{*}{$0.071^{c}$} \\
\hline Female & $12(21.4)$ & $5(9.1)$ & \\
\hline \multicolumn{4}{|l|}{ Educational level } \\
\hline High school graduates or lower & $45(80.4)$ & $44(80)$ & \multirow[t]{2}{*}{0.962} \\
\hline Academic education & $11(19.6)$ & $11(20)$ & \\
\hline \multicolumn{4}{|l|}{ ASA } \\
\hline 1 & $51(91.1)$ & $50(90.9)$ & \multirow[t]{2}{*}{0.976} \\
\hline 2 & $5(8.9)$ & $5(9.1)$ & \\
\hline \multicolumn{4}{|l|}{ History of surgery } \\
\hline$\leq 2$ & $51(91.1)$ & $53(96.4)$ & \multirow[t]{2}{*}{0.251} \\
\hline$>2$ & $5(8.9)$ & $2(3.6)$ & \\
\hline \multicolumn{4}{|l|}{ History of anesthesia } \\
\hline$\leq 2$ & $53(94.6)$ & $53(96.4)$ & \multirow[t]{2}{*}{0.662} \\
\hline$>2$ & $3(5.4)$ & $2(3.6)$ & \\
\hline \multicolumn{4}{|l|}{ History of drug abuse } \\
\hline Yes & $14(25)$ & $18(32.7)$ & \multirow[t]{2}{*}{0.369} \\
\hline No & $42(75)$ & $37(67.3)$ & \\
\hline \multicolumn{4}{|l|}{ History of alcohol abuse } \\
\hline Yes & $9(16.1)$ & $10(18.2)$ & \multirow[t]{2}{*}{0.768} \\
\hline No & $47(83.9)$ & $45(81.8)$ & \\
\hline
\end{tabular}

Table 2: Comparison of mean BIS at studied time intervals between two intervention Groups A and B

\begin{tabular}{|c|c|c|c|c|c|}
\hline \multirow[t]{2}{*}{ Group time } & \multicolumn{2}{|c|}{ Intervention Group "A" $(n=56)$} & \multicolumn{2}{|c|}{ Intervention Group “B” $(n=55)$} & \multirow[t]{2}{*}{ p-value ${ }^{* *}$} \\
\hline & Mean \pm SD & $\mathbf{p}^{*}$ & Mean \pm SD & $\mathbf{p}^{*}$ & \\
\hline Before surgery (baseline) & $98.50 \pm 4.419$ & - & $98.98 \pm 1.421$ & - & 0.443 \\
\hline 5 min after surgery & $63.71 \pm 11.145$ & $<0.001$ & $60.62 \pm 15.172$ & $<0.001$ & 0.223 \\
\hline 10 min after surgery & $63.30 \pm 14.625$ & $<0.001$ & $62.55 \pm 13.210$ & $<0.001$ & 0.775 \\
\hline 15 min after surgery & $65.09 \pm 10.618$ & $<0.001$ & $63.33 \pm 12.822$ & $<0.001$ & 0.432 \\
\hline 30 min after surgery & $66.73 \pm 11.702$ & $<0.001$ & $66.20 \pm 11.834$ & $<0.001$ & 0.812 \\
\hline 40 min after surgery & $65.63 \pm 10.565$ & $<0.001$ & $68.13 \pm 11.379$ & $<0.001$ & 0.232 \\
\hline 60 min after surgery & $65.25 \pm 12.556$ & $<0.001$ & $<0.001 \pm 12.035$ & $<0.001$ & 0.291 \\
\hline
\end{tabular}

*Repeated measures test. **Independent T test. SD: Standard deviation 
Table 3: The frequency of "consciousness during operation" between two intervention Groups " $\mathrm{A}$ " and "B" using Brice questionnaire

\begin{tabular}{|c|c|c|c|c|c|c|}
\hline \multirow[t]{3}{*}{ Brice questionnaire questions } & \multicolumn{4}{|l|}{ Frequency (\%) } & \multirow[t]{3}{*}{ OR } & \multirow[t]{3}{*}{$\mathbf{p}$} \\
\hline & \multicolumn{2}{|l|}{ Yes } & \multicolumn{2}{|l|}{ No } & & \\
\hline & $\begin{array}{l}\text { Intervention Group } \\
\text { "A" }\end{array}$ & $\begin{array}{l}\text { Intervention Group } \\
\text { "B" }\end{array}$ & $\begin{array}{l}\text { Intervention Group } \\
\text { "A" }\end{array}$ & $\begin{array}{l}\text { Intervention Group } \\
\text { "B" }\end{array}$ & & \\
\hline $\begin{array}{l}\text { 1. Do you remember anything } \\
\text { before going to sleep? }\end{array}$ & $46(82.1)$ & 43 (78.18) & $10(17.85)$ & $12(21.81)$ & 0.779 & 0.601 \\
\hline $\begin{array}{l}\text { 2. Do you remember anything } \\
\text { after waking up? }\end{array}$ & $10(17.85)$ & $14(25.45)$ & $46(82.1)$ & $41(74.54)$ & 1.57 & 0.333 \\
\hline $\begin{array}{l}\text { 3. Do you remember anything } \\
\text { between going to sleep and } \\
\text { waking up? }\end{array}$ & $19(33.92)$ & $12(21.81)$ & $37(66.07)$ & $43(78.18)$ & 0.543 & 0.158 \\
\hline $\begin{array}{l}\text { 4. Did you dream during your } \\
\text { procedure? }\end{array}$ & $4(7.14)$ & $5(9.09)$ & $52(92.85)$ & $50(90.90)$ & 1.30 & 0.708 \\
\hline $\begin{array}{l}\text { 5. Did you feel any pain during } \\
\text { your procedure? }\end{array}$ & $5(8.92)$ & $5(9.09)$ & $51(91.07)$ & $50(90.90)$ & 1.02 & 0.976 \\
\hline $\begin{array}{l}\text { 6. Did you hear anything during } \\
\text { your procedure? }\end{array}$ & $21(37.50)$ & $9(16.36)$ & $47(83.92)$ & $34(61.81)$ & 3.22 & 0.010 \\
\hline
\end{tabular}

OR: Odds ratio

of consciousness during surgery in intervention Group "A" was not statistically different from the intervention Group "B." However, there was a significant difference in question 6 of the questionnaire, which refers to hearing during surgery, and the chance of hearing during surgery in intervention Group " $\mathrm{B}$ " was 3 times higher than the intervention Group "A" (odds ratio $=3.22,95 \%$ confidence interval: 1.32-7.79)

\section{DISCUSSION}

In the present study, the results of Brice questionnaire, answered by the patients, showed that $46(82.1 \%)$ in Group "A" and $43(78.18 \%)$ in Group "B" remembered the events before anesthesia. Such high statistics point out that the anesthetic personnel should not allow the surgeon to start incision and painful procedures until the patients have reached the optimum depth of anesthesia [12].

In terms of the events during consciousness, 10 (17.85\%) in Group "A" and $14(45.25 \%)$ in Group "B" stated that they remembered the events during consciousness, which emphasizes that the anesthetic team should maintain the anesthetic level and the depth of anesthesia at an optimum level until the end of the last suture and painful procedure on the patient.

Regarding sleep/dreaming during anesthesia, 4 (7.14\%) in Group "A" and $5(9.09 \%)$ in Group "B" were dreaming a green landscape and a white and snowy environment. In the study of Nasiri et al., the rate of dreaming during anesthesia was $3.2 \%$, which is close to our statistics [13].

Peter et al. [2004] reported a prevalence of dreaming at $6 \%$ and other studies reported a range of $1.1 \%-10.7 \%$, which was more common in younger patients and outpatient surgeries [14-16]. The difference in the incidence of this complication among studies is probably related to the type of anesthetic drug used. It can also be linked to the fact that most patients may have forgetfulness due to using midazolam before induction or it could be because of lack of an instrument for monitoring the depth of anesthesia in other studies that reduced the specific conditions of consciousness during anesthesia, such as dreaming.

Furthermore, 5 patients (8.92\%) in Group "A" and 5 (9.09\%) in Group "B" reported having experienced pain during surgery, which was $0.33 \%$ in the study by Tavakolian et al., which is not consistent with the results of our study, probably due to the type and amount of prescribed opioids [17].

Finally, regarding hearing during anesthesia, 21 (37.5\%) in Group "A," and $9(16.36 \%)$ in Group "B" stated that they heard sounds during anesthesia and surgery. The results of the study of Arefian and Fathi showed that one of the most common conditions associated with consciousness during anesthesia was hearing of employees' conversation and the sound of devices $(2.8 \%)$ and the difference in these statistics could be due to the type of surgery that was cesarean section in this study [18].

In the study of Rezanjeed et al., $40 \%$ of the patients referred to cases indicating consciousness during anesthesia that is in line with the present study [19].

With comparing the experience of consciousness during anesthesia, Table 3 showed that there were no statically significant differences between two groups for questions 1 to 5 (regarding to remembering the events before going to sleep, after sleep, during sleep, dreaming and feeling pain during the operation) but, there was a significant difference in the 6th question (regarding to hearing of sounds during anesthesia). Also the chance of hearing sounds during anesthesia in group B (Propofol-alfentanil group), was 3 times greater than group A (Thiopental-Remifentanil group).. Therefore, it can be concluded that the use of thiopental for induction and remifentanil for maintenance can be associated with less complication of hearing sounds during anesthesia.

In the study of Smith and Ashworth on desflurane, isoflurane, and propofol in outpatient surgeries, there was no awareness during operation in anesthesia with propofol and isoflurane [20], while in the study of Mehmandoost et al., 4 (9.8\%) of the propofol group and 3 (6.7\%) of the isoflurane group remembered some cases of surgery, but there was no significant difference between the two groups [21]. Since we used isoflurane in both Groups "A" and "B," we could not compare propofol with isoflurane.

In a study by Abboud et al., the effect of propofol and isoflurane as an anesthetic maintenance agent was compared on 74 pregnant women with cesarean section in two groups. In this study, the incidence of consciousness during operation and recovery time was not different between the two groups [22].

Findings of the study by Shahi et al. 2015 showed that 18 patients $(2.6 \%)$ remembered something between sleeping and consciousness, $59(8.8 \%)$ of them dreamed, $19(2.7 \%)$ felt pain, and $23(4.3 \%)$ had auditory consciousness. The results showed that there was only a significant relationship between auditory consciousness and surgical site, dreaming, and weight $(\mathrm{p}<0.05)$, which is consistent with the results of our study [23]. 
The results of the study of Szostakiewicz et al. showed that, of 199 studied patients, about 17 (5.8\%) dreamt during anesthesia. The events that patients remembered after anesthesia included $25.63 \%$ - the events of the recovery room, $8.5 \%$ - the anesthetist's voice, $7.4 \%$ - delivery to the recovery room, $7.03 \%$ - pain, $5.03 \%$ - the transfer to the bed, $4.52 \%$ - conversation with anesthesiologist regarding surgery, $3.53 \%$ - waking up in the operating theater, $2.02 \%$ - conversation with the anesthesiologist in the operating theater, $1.15 \%$ - conversation with the operating theater personnel, $1.15 \%$ - the lamps of operating theater's ceiling, $1.15 \%$ - respiration with mask, 1.01 - cold, 1.01\% throat pain, and $1.01 \%$ - nausea . According to the statistics, the incidence of consciousness during surgery is reported low, and onthe-spot monitoring, such as checking vital signs and measuring the concentration of inhalable gases, can both be helpful in assessing consciousness during anesthesia [9].

Conventionally, hemodynamic parameters, such as blood pressure and heart rate, or objective evidence such as patient mobility, tearing,or sweating were used to assess the depth of anesthesia, but these methods are not accurate and are always subject to errors. For example, the use of beta-blockers or the presence of associated diseases, such as hypertension or the use of agents inducing hemodynamic changes during anesthesia (like tachycardia caused by isoflurane), causes an error when relying on these parameters. In addition, hypovolemia, hypoxia, hypercapnia, and inadequate analgesia, instead of an inadequate anesthetic, can have the same presentations. Although targeted movements during anesthesia may indicate inadequate anesthetic, they do not indicate consciousness and are most often due to spinal reflex [24]. In this study, in addition to traditional methods and Brice questionnaire, BIS monitoring was used to evaluate the depth of anesthesia.

The results of this study showed that in Group "A," the BIS score at $\min 5,15,30,40$, and 60 was 63.71, 63.30, 65.09, 66.73, 65.63, and 65.25 , respectively. Using repeated measure ANOVA test, a significant difference was observed among the time points in Group "A" ( $p=0.0001)$.

In Group "B," the BIS score for BIS at min 5, 15, 30, 40, and 60 was 60.62, $62.55,63.33,66.20,68.13$, and 67.73 , respectively. Using repeated measure ANOVA test, there was a significant difference between different time points in Group " $\mathrm{B}$ " ( $\mathrm{p}=0.0001)$. However, there was no significant difference between the two Groups " $A$ " and " $\mathrm{B}$ " at different time points $(\mathrm{p}>0.05)$.

It can be concluded that if a patient receives thiopental sodium or propofol for the induction or receives remifentanil or alfentanil for maintenance, there will be no significant difference in the depth of anesthesia in the patient, and both drugs will have the same effect in anesthesia depth.

In the study of Kamalie et al., among 107 patients with anesthesia without BIS monitor, 8 (7.4\%) had anesthesia awareness. However, in the group anesthetized with BIS monitor, none of the patients experienced anesthesia awareness $[8,25]$.

\section{CONCLUSION}

The results of this study showed that none of the drugs used for induction (thiopental sodium or propofol) or for maintenance (remifentanil or alfentanil) have an advantage over the other in maintaining the depth of anesthesia at the desired levels, and the use of the above drugs causes similar depth of anesthesia in the subjects undergoing surgery.

\section{ACKNOWLEDGMENTS}

We hereby thank and appreciate the deputy chairman of the Research Department of Dezful University of Medical Sciences, the staff of the Ganjavian hospital's operation theater, and all the patients who collaborated with us in this project.

\section{IMPLICATION}

Consciousness during anesthesia is a non-reversible complication that may expose the patient to severe, long-term, emotional injuries and post-traumatic stress.

\section{AUTHORS' CONTRIBUTION}

Study concept and design: Farhad Nanaei. Analysis and interpretation of data: Maryam Dastoor Poor, Zohre Sekhavat Pour, and Sara Adarvishi. Manuscript preparation: Zohre Sekhavat Pour, Sara Adarvishi, and Farhad Nanaei. Collection of data: Zohre Sekhavatpour and Farhad Nanaei, Critical revision: Nanaei, Adarvishi, Dastoor Poor, and Sekhavat Pour

\section{FINANCIAL DISCLOSURE}

The authors declare that there is no conflict of interest.

\section{FUNDING/SUPPORT}

This study was financially supported by Vice-Chancellor, Dezful University of Medical Sciences, for research and technology.

\section{REFERENCES}

1. Sanders RD, Tononi G, Laureys S, Sleigh JW. Unresponsiveness $\neq$ unconsciousness. Anesthesiology 2012;116:946-59.

2. Yu H, Wu D. Effects of different methods of general anesthesia on intraoperative awareness in surgical patients. Medicine (Baltimore) 2017;96:e6428.

3. Singla D, Mangla M. Incidence of awareness with recall under general anesthesia in rural india: An observational study. Anesth Essays Res 2017;11:489-94.

4. Lopes-Pimentel P, Koo M, Bocos J, Sabaté A. The bilateral bispectral and the composite variability indexes during anesthesia for unilateral surgical procedure. Saudi J Anaesth 2017;11:49-53.

5. Whitlock EL, Villafranca AJ, Lin N, Palanca BJ, Jacobsohn E, Finkel KJ, et al. Relationship between bispectral index values and volatile anesthetic concentrations during the maintenance phase of anesthesia in the B-unaware trial. Anesthesiology 2011;115:1209-18.

6. Payas A, Kaygusuz K, Düger C, İsbir AC, Kol İÖ, Gürsoy S, et al. The effects of bispectral index and neuromuscular blockade monitoring on the depth of anaesthesia and recovery in cardiac patients under desflurane anaesthesia. Turk J Anaesthesiol Reanim 2013;41:211-5.

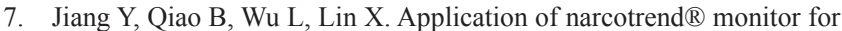
evaluation of depth of anesthesia in infants undergoing cardiac surgery: A prospective control study. Braz J Anesthesiol 2013;63:273-8.

8. Kamali A, Shokrpour M, Sh P, Moshiri E, Taheri-Nejad MR, Dadashpour N, et al. Determining the effect of BIS monitoring on level of awareness during anesthesia in women undergoing elective caesarean section. Arak Med Univ J 2015;17:56-63.

9. Szostakiewicz KM, Tomaszewski D, Rybicki Z, Rychlik A. Intraoperative awareness during general anaesthesia: Results of the observational survey. Anaesthesiol Inten Ther 2014;46:23-8.

10. Liu W, Thorp T, Graham S, Aitkenhead A. Incidence of awareness with recall during general anaesthesia. Anaesthesia 1991;46:435-7.

11. Flaishon R, Windsor A, Sigl J, Sebel P. Recovery of consciousness after thiopental or propofolbispectral index and the isolated forearm technique. J Am Soc Anesthesiol 1997;86:613-9.

12. Nasiri E, Padashi S, Majd MK. Awareness during general anesthesia for caesarian section. J Mazandaran Univ Med Sci 2006;16:57-64.

13. Nasiri E, Padashi S, Majd MK. Awareness during general anesthesia for caesarian section. J Mazandaran Univ Med Sci 2006;16:57-64.

14. Sebel PS, Bowdle TA, Ghoneim MM, Rampil IJ, Padilla RE, Gan TJ, et al. The incidence of awareness during anesthesia: A multicenter United States study. Anesth Analg 2004;99:833-9.

15. Myles P, Symons J, Leslie K. Anaesthetists' attitudes towards awareness and depth-of-anaesthesia monitoring. Anaesthesia 2003;58:11-6.

16. Cohen NH. Anesthetic depth is not (yet) a predictor of mortality! Anesth Analg 2005;100:1-3.

17. Tavakolian A, Ghodrati Z, Zand F, Jahanmiri F. Assessment of the incidence of awareness during general anaesthesia in open heart surgery in the hospitals of Shiraz university of medical sciences. J Iran Soc Anasthesiol Inten Care 2011;2:39-46.

18. Arefian N, Fathi M. Evaluation of prevalence of awareness during general anesthesia for cesarean section during 2005-2006 in Shohada 
hospital. JAUMS 2007;5:1267-71.

19. Rezanejad JB, Farzan B. Study of incidence rate of awakening and remembering during general anesthesia. Yafteh 2006;4:???

20. Ashworth J, Smith I. Comparison of desflurane with isoflurane or propofol in spontaneously breathing ambulatory patients. Anesth Analg 1998;87:312-8.

21. Mehmandoost M, Naghibi K. Comparative study of the effects of two anesthetic methods with propofol and isoflurane on mother's awareness during the operation and APGAR score in the newborns delivered by elective cesarean section. J Isfahan Med Sch 2013;31:228

22. Abboud T, Zhu J, Richardson M, Silva E, Donovan M. Intravenous propofol vs thiamylal-isoflurane for caesarean section, comparative maternal and neonatal effects. Acta Anaesthesiol Scand 1995;39:205-9.

23. Shahi S, Fard MF, Sadeghi M, Shoeibi G. The incidence of awareness during general anesthesia. Anesthesiol Pain 2013;4:47-54

24. Nalini, R Ezhilramya J. A comparative study of efficacy and safety of lornoxicam and diclofenac as postoperative analgesics after mastoidectomy surgery. Int J Pharm Pharm Sci 2017;9:77-83.

25. Brethis CS, Thamizharasan S, Sridevi SA, Kalaiselvi B, Singh MB, Vijaykumar K. A prospective study of the pattern of use of antimicrobial agents in surgical PROPHYLAXIS in a tertiary care centre. Int J Pharm Pharm Sci 2017;9:283-7 